\title{
The Effect of recreation sprout program on Some Psychological Variables of the Optically Disabled
}

\section{Dr/ Ahmed Mohamed Hashem}

\section{The Introduction and the Research Problem}

The God creates the Human at the best creation and the best shape, and for the God's wisdom and for a reason the God only knows the God despoils one of these blessings or a little of it or a lot, despoiling one of these many blessings is in fact a kind of disability, the disabled is "the person who one of his vital organs in his body was despoiled as a result of disease or infection or heredity, resulted from that he became unable to satisfy his needs" upon this the disabled isn't that person with the appeared handicap, as the blind, the deaf and the crippled but it's the derogation of each vital function in the human body, there are several types of disability such as auricular, optical, kinetic and mental disability.

Ahmed Adam and Ahmed Maher (2005) both agree on that, the last years faced a scientific and practical importance with the disability and the disabled with considering that the individual is a social creature can't live away from the others, but needs the positive interaction with them and associate with them in order to affect in them and affected by them which achieve the stability and the social security, that importance refluxes to the increased persuasion in the different societies that the disabled as the other people in the society, have the right to live, grow and in services to the maximum limit of their abilities and energies, and this care refluxes to also the different vision of the society to these individuals. (3:9)

Hassan Elba tea (2010) referred to that, the issue of learning the people with the special needs and qualifying them represent a civilized challenge for the nations and societies, because it's a humanistic issue at the first rank, could obstruct the nations' progress, considering that the disabled represent a ration which isn't less than $10 \%$ of the total population over the local and international 
level, these huge numbers of the disabled formulate an educational loss, threaten the national and international economy, and in accordance with the published statistics on the internet the disabled are 600 million person in the world, more than $80 \%$ of them in the developed countries. (12:24)

\section{Ramadan Mohamed (2000) and Abd Elhameed} Sharaf (2001) both agree on that, whatever the numeration differentiated and the numbers collided the biggest problem represented in the tiny amount of these disabled who get services and care in the developed countries, as those who get the needed services in this field represent only $1.9 \%$ of those with the special needs, as it needs institutions whatever governmental or nongovernmental institutions, in addition to its extremely expensive costs, and that issue requires training, residence and employees, which require the necessity of social cooperation and interconnection between all segments of the society in taking care of the special needs individuals, with searching for a granting sides to try to enter these categories and most of them of poor and limited income in the improvement process instead of being a dependent on their country. $(1: 17)(20: 81)$

Abu Elnga Ezz Eldin (2003) mentions about the definition of the General Association of the United States in announcing the disabled rights of 9 December 1975 which states on that, the disabled are a group of people who aren't able to depend on themselves totally or partially in accomplishing the contingent work and the sportive participations except with help and special facilitates presented to them to merge them in the public life according to the disability level or the shortage whatever it was organic, mental or physical. (1:216)

Kawthar Hussein (2003) mentions that, Disability has reactions on the disabled individual's life because the social problems caused by the disability considered the cause of the extreme effect on him as it prevent him from achieving his psychological compatibility and it has psychological effects related to the sensitive and polemical sides such as feeling with pain, grief and 
incompleteness in addition to the polemical insensibleness and the neurological tension but also the disability affect the disabled personality in general. (3:24)

Hosny Elgbely (2005) refers to that, it's able to consider the optically disabled are a special category when comparing with their counterparts in the other categories, the optical disability may be one of these factors with the negative effect on the optically disabled feelings, as he find a difficulty in describing his feelings towards the others and towards himself, because the disability creates a feeling on unconfident of himself, that imposes him to separate from the society he lives in, also the blindness puts the optically disabled in a social isolation, as he can't interact with the surrounding people, or with the outer environment with all its variables. (11:13)

The self-concept is the individual's thinking about himself or realizing himself, his personal aspects, abilities and the power and weak sides in him, the insufficiency of the self-concept of the blinds caused by the dominance and the outer control on him and that means he is unconfident in himself, his possibilities and depending on the other and reduction in the successful experiences that he passes. (45:53)

Ekhlas Abd Elhafez (2002) refers to that, the physical education is an integrated educational activity as whole and works on improving it from all physical, mental, psychological, social and educational and others, so the raisers should take care of the physical activities suitable for the optically disabled and to be an essential part in preparing them to achieve the highest levels of the psychological health of them. (5:19)

Samira Abu Zeid (2001) mentions that, feeling with difference from the ordinary people causes a psychological anxiety and that because the optically disabled disability imposes a determined world on him and when he wants to get out of his narrow world and incorporates in the world of the people who see he find himself needing to be independent and free, but when he does this he hit with his disability effects that push him again to his tiny 
world whence he imposed to sharp psychological disturbances as a result of his feeling of his disability to move completely free and to control

his environment as the person who can see control it, as the optically disabled looks disturbed and confusion is obvious. (15:54)

Thus, this category need programs, educational, training, qualified, medical and cultural service, as the nations' civilization measured by the amount of what it present of educational and health care of the society individuals in general and the disabled especially, the degree of this care differentiated according to the prevailing economical and thinking basics in these societies, also there is an important problem which is the prevailing thought in some societies that providing the services related to disabled and improving it is a service, the truth is that we must appreciate and be sure that these services are a right of the individual's rights and not a favor in providing services. (11:32)

The researcher sees that the relief sportive activities considered a rich field that the individual acquired the psychological and social values of it, so providing the suitable sportive programs for the optically disabled considered a duty of the society towards his sons, as the success of these programs depends greatly on the extent of understanding the responsible persons the nature of the optical disability, the researcher is interested in studying some psychological sides of the optically disabled children as they represent a big sector of the society, and they should have the sufficient care such as the others, as it was declared the absence of sportive programs or activities related to them which required the necessity of interested in them and taking care of them and putting special programs that suit the disability type to contribute in achieving the psychological compatibility and the suitable psychological health of this category.

\section{The Research Aim:}

The research aims at recognizing a proposed sportive relief program effects on some psychological variables and of the disabled optic 
The Research Assumptions:

- There are differences statistically significant between the average pre and post measure at the level of the optically disabled under search.

- There are differences statistically significance between the average pre and post measures at the level of self-effectiveness of the optically disabled under search.

\section{The research sample:}

The research used the experimental metrology as it is the suitable curriculum for the research nature and that by using the experimental design for one group and that for achieving the research objectives and assumptions.

\section{The rsearch population and} sample:

The research contains the optically disabled children at Elnour and Elaml school for thhose with the spcial needs in Giza at Elshekh Zayed city in the academic year 2012/2013, the society amount was (60) male and female child, their ages ranged between 9 to 12 years old, the researcher chose a sample of (40) child of the children in addition to (20) child to make the polite study of the research.
To collect the data of the research the researcher used the following tools First: the psychological measures

1- The anxiety measure for the blind prepared by/ Adel Elashwal and Abd Elaziz Elshakhs

2- Self-understand measure of the children prepared by Adel Elashwal

The sportive recreation sport Program content Warm-up exercises:

It's necessary to start with warm-up exercises before doing any sportive activity to avoid the injury and also the objective of doing warm-up exercises activating the blood circuit and generate the energy in the body to be able to do the physical activity in addition to give the body the flexibility and the maximum selfpreparation for the training and alert the different body systems to do its roles and also it's necessary to perform these exercises moderately to not make the students exhausted.

\section{Physical Exercises:}

These exercises are a great base for the general and special physical preparation for all the activities and it also contribute greatly in raising the 
physical fitness of the students through improving the physical specifications for them such as power, speed, affordance, fitness, flexibility, balance and compatibility. It doesn't require a high amount of abilities or preparation or special talents for performing it, so it is possible to be performed for all levels, and it also doesn't need qualifications or a special place to do it.

\section{The easy games:}

These games

distinguished by fun and joy in addition to its educational value and its contribution in upgrading the students' abilities, and it also works on increasing the connection and cooperation between the students through the team participation in these sports.

\section{The Games in groups:}

The researcher chose some team sports that could be played in the school and its possibilities are available, these sports are: volleyball, handball, goal ball (bell) and also acquiring the students the skills that these sports include it and applying it in competitions related to these sports contribute in acquiring the students a lot of desired pedagogical aspects as cooperation, self-confidence, self-compatibility and leadership.

\section{Relaxation Exercises:}

The importance of relaxation exercises is that it's a shaking moves of the body organs usually performed after the exertion exercises or the power exercises that distinguished by the increased muscular nervous, as these exercises aim to muscles' relaxation which work on accelerating supporting it with blood, which lead to feed the muscles, which resulted in increasing the ability to work and improve the muscular respond.

And it also reduce the anxiety sharpness of the students, control their motivations and get rid of the exertion.

\section{First: Results' Show}


Schedule (1)

The Difference Significance between the Pre and Post Measure at the Anxiety Level of the Blind in the Sample Under Search

$(n=40)$

\begin{tabular}{l|l|l|l|l|l|l|l|l|}
\hline \hline Variables & \multirow{2}{*}{$\begin{array}{c}\text { Measuring } \\
\text { unit }\end{array}$} & \multicolumn{2}{|c|}{ Pre measure } & \multicolumn{2}{|c|}{ Post measure } & \multicolumn{1}{|c|}{$\begin{array}{c}\text { Differences } \\
\text { between } \\
\text { averages }\end{array}$} & (t) & $\begin{array}{c}\text { Significance } \\
\text { level }\end{array}$ \\
\cline { 3 - 8 } & & Mean & deviation & Mean & deviation & \\
\hline \hline $\begin{array}{l}\text { Anxiety } \\
\text { measure } \\
\text { of the } \\
\text { Blind }\end{array}$ & degree & 2.19 & 141.80 & 2.60 & 125.11 & 16.69 & 4.55 & significant \\
\hline \hline
\end{tabular}

(t) scheduled value at the significance level $(0.05)=1.708$

It's obvious from the blind students of the

schedule (1) that there are sample under search as (t)

differences statistically calculated value (4.55) at an

significant between the improving rate of $(13.34 \%)$

averages of the pre and post and for the behalf of the post

measures at the anxiety level of measure.

Schedule (2)

The Difference Significance between the Pre and Post Measure at the Self-Understanding Level of the Blind in the Sample under

Search $(n=40)$

\begin{tabular}{|c|c|c|c|c|c|c|c|c|}
\hline \multirow[t]{2}{*}{ Variables } & \multirow{2}{*}{$\begin{array}{l}\text { Measuring } \\
\text { unit }\end{array}$} & \multicolumn{2}{|c|}{ Pre measure } & \multicolumn{2}{|c|}{ Post measure } & \multirow{2}{*}{$\begin{array}{l}\text { Differences } \\
\text { between } \\
\text { averages }\end{array}$} & \multirow[t]{2}{*}{ (t) } & \multirow{2}{*}{$\begin{array}{l}\text { Significance } \\
\text { level }\end{array}$} \\
\hline & & Mean & deviation & Mean & deviation & & & \\
\hline $\begin{array}{l}\text { Self- } \\
\text { understanding } \\
\text { measure of } \\
\text { the Blind }\end{array}$ & degree & 3.72 & 38.53 & 2.18 & 45.14 & 6.61 & 3.70 & significant \\
\hline
\end{tabular}

(t) scheduled value at the significance level $(0.05)=1.708$ It's obvious from rate of $(17.15 \%)$ and for the schedule (2) that there are differences statistically significant between the averages of the pre and post measures at the selfunderstanding level of the blind students of the sample under search as $(\mathrm{t})$ calculated value (3.70) at an improving behalf of the post measure.

\section{Results Discussion}

It's shown through the results of the schedule (1) the that there are differences statistically significant between the averages of the pre and post measures at the psychological anxiety level of the blind 
students and for the post measure, the researcher refluxes this result to that, the relief sportive program and what it contains of different activities contributed positively in lowering the anxiety level of the sample under search, so the results showed that there are differences in the anxiety degree before and after applying the program and towards the post measure.

The researcher sees that the improvement refluxes to that, the relief sportive program involves relaxation exercises that contribute positively in making the optically disabled feel with repose and tranquility as these exercises helped in lowering the speed of the heart beats, get rid of stress and limit the physiological variables' effect in the body that lead to making the disable feel with stress and anxiety.

About this Sohair Kamel Ahmed (1999) refers to that, the optical disability changes the mental life of the individual as a whole and the social in adaption that the optically disabled suffers from it which appear in increasing the psychological anxiety of him refluxes to the optical and intellective isolation that he feels with it. (16:52)

Ehab Elsaby (2003) sees that, losing sight and especially in the primary stages of the age makes the disabled loses his self confidence and not feeling with safe and being isolated and introversive. (11:62)

This result agrees with the study results of Ahmed Adel Lofty (2009) (2), Ahmed Mohamed Aly (2002)(4), Aml Fahmy (2006)(8) that referred to the positive effect of the guiding sportive activities on lowering the anxiety of the optically disabled students.

So that, the first assumption is achieved which state on that, there are differences statistically significant between the averages of the pre and post measures at the anxiety level on the psychological future of the optically disabled of the sample.

It's obvious from schedule (2) that there are differences statistically significant between the averages of the pre and post measures at the selfunderstanding level of the blind students of the sample under search for the behalf of the post measure, the 
researcher refluxes this result to that the sportive program that encourages the blind to work inside the program and motivate it, as the selfunderstanding is the person's thought about himself or his recognition to himself, it's affected by his feelings' nature, his directions, personal aspects, abilities and his weak and strength points, and the shortage in the self-concept of the blind because of dominating the outer control on it which means his self un confidence, his qualifications, his dependence on the others and reduction in the successful expertise that he passes it and this what the researcher avoided in the sportive program by motivating the blinds.

Each of Awatef Ibrahim Elhneedy, Mnal Abd Elfattah Mohamed (2006) agree on that, the optical disability has negative effects on the individual's self-concept and on his psychological health, that leads consequently to the bad personal and social adaption and the psychological disturbance, and as a result of feeling with disability, inferiorities, depression, stress, losing the feel of belongingness and safety, on another side that is totally different from the previous one such as, compassion, increased protection, neglecting and ignoring, that lead to escalating their feeling of disability and insufficiency and difference from the others. Despite of the blindness may make the life more difficult, the true of losing sight doesn't interpret what the optically disabled faces of physical, social and psychological difficulties, as the greatest important factor is found in the person himself and his relation with the society and his directions towards it. (23:37)

Each of Sohai Kamel (1999) and Abd Elrhman Ibrahim (2003) agree on that, the social compatibility associated with the individual's acceptance within the society by the others and realizing the person the relation that connect between him and the society parts according to its difference and reach a case of balance in impregnation, bereavement, buffetings and interactions and the individuals' ability to be appropriate with the environment changes and the surrounding conditions inverse his case of the polemical, 
psychological, mental and behavioral balance.

This study results agree with Magdy Aziz (2007), the optical disability has negative effects on the individual's selfconcept and on his psychological health, that leads consequently to the bad personal and social adaption and the psychological disturbance, and as a result of feeling with disability, inferiorities, depression, stress, losing the feel of belongingness and safety, on another side that is totally different from the previous one such as, compassion, increased protection, neglecting and ignoring, that lead to escalating their feeling of disability and insufficiency and difference from the others. Despite of the blindness may make the life more difficult, the true of losing sight doesn't interpret what the optically disabled faces of physical, social and psychological difficulties, as the greatest important factor is found in the person himself and his relation with the society and his directions towards it. (26:487)

So that, the second assumption is achieved, which states on that, there are differences statistically significant between the averages of the pre and post measures at the self-concept level of the blind students of the sample under search.

\section{Conclusions:}

1. The proposed sportive program affected positively on the psychological anxiety level of the optically disabled under search.

2. The proposed sportive program affected positively on the self-concept level of the optically disabled under search.

\section{Recommendations:}

1. Considering to provide the suitable sportive programs for the optically disabled to contribute in achieving the good psychological health to this category.

2. Caring the responsible with providing all possibilities needed such as playgrounds and sportive tools to do sportive activities by the optically disabled.

3. Working on providing the suitable opportunities to achieve the success expertise to the optically disabled which give him the self-confidence and the compatibility with the society

\section{References}

1- Abo Elnaga Amed Ezz

El Din: Curriculums in The 
Physical Education (for healthy and disabled persons), Shagrat Eldor Library, Mansoura 2003.

\section{2- Ahmed Adel Lotfy}

"Sportive Relief Program to Improve Some Physical Fitness Elements and the Electric Activity of the Working Muscles of the Blind" MBA desertion, Faculty of Physical Education, Tanta University, 2009.

3- Ahmed Maher, Ahmed Adam (2005): The Physical Education for the Blind, Anglo Egyptian Library, Cairo.

4- Ahmed Mohamed Aly (2002) "The Effect of Using the Place Directing and the anthropomorphic on the speed of Learning the Basics of Judo for the Optically Disabled and the Intelligence Level of Procurement" MBA desertion, Faculty of Physical Education, Alexandria University.

5- Ekhlas Mohamed Abd Elhafeez (2002):

Psychological Direction and Guide in the Physical Field, Book Publishing Center, Cairo. 6- Osama Riad Aly (2000): Applied Basics of the Disabled Sport, Dar Elfekr Arabic, Cairo.

7- The Pedagogical

Curriculums for the Nurseries: a suggested working sheet for the Arabic Meeting to Coordinate the Cooperation and working in the Nurseries Field.

8- Aml Mohamed Fahmy (2006): The Effect of a Sportive Program on some Behavioral Problems for the optically disabled at the secondary school in Bani Sweif, unpublished MBA, Faculty of Physical Education, Minia University.

9- Ayman Ramadan

Zahran: The Efficiency of the Integrated Cure in Improving some Life Skills for a sample of the mentally disabled children who accepting learning, published scientific research, Faculty of Physical Education, The Saudi King University, 2006.

10- Ihab Abd Elaziz Elbblawy (2001): The Blind Anxiety, its diagnose and cure", the special raising (2), Cairo, Zahraa Elshhrouk Library.

11- Ihab Mohamed Elsaby (2003): The Efficiency of a Relief Sportive Program to Adjust the Withdrawal Behaviour of the Blind" unpublished MBA desertion, Faculty of Physical Education, Tanta University. 
12- Hassan Elbateaa Abd Elaty: The Educational Technology of the Disabled with the Special Needs" Knowledge Mgazine, Ein Shams University, 2010.

\section{3- Hassan Elgebaly}

(2005): The Blind and the Deaf between Oppression and Grandiosity, Cairo, Anglo Egyptian Library.

14- Hanan Saeid Elsayed (2007) titled at, "The Life Pressures and Strategies of Facing it and their Relation with the Personal Aspects for Blind sample in a Guiding Applied Study, MBA, Faculty of Arts, Alexandria University. 15- Samira Abu Zeid Nagdy (2001): Program and Methods of Raising the Disabled Child before Study, Edition 1, Cairo, Zahraa Elshrk Library.

16- Sohair Kamel Ahmed (1999): Child Growth Psychology, Practical Theory and Applications, Alexandria Center for Book, Cairo (17)

17- Ramadan Mohamed Elkzafy: Disability Psychology, The Opened University, Trablus, 2000

18- Adel

Mohamed (2004) The Sensitive Disability, Dar
Elrashad for Printing and Publishing

19- Adel Ezz Eldin Elshwal (1984): Self Concept Measure of the Children, Instructions Notebook, Egyptian Anglo Library, Cairo

20- Abd Elhameed Sharaf: The Physical and Kinetic Education of the Healthy Children and the Disability Challenging between Theory and Application, Book Center for Publishing, Cairo, 2001

21- Abd Elrhman Ibrahim Hassan (2003): Blind Raising and Learning them, Book World, Cairo

22- Abd Elmotaleb Amin Elkoreity (2001): Special Needs Psychology and Raising them, Cairo, Dar Elfekr Arabic 23- Awatef

Elhneedy, Manal Abd Elfattah Mohamed (2006): Children with Optical Disabilities the Theory and Method, Dar Elfekr Al Arabic, (24)

24- Kawthar Hussein Kojak (2003): The Pedagogic of the Early Childhood in the Philosophy, Dar Elfekr Al Arabic

25- Magda Ebeid Elsayed (2000): Learning the Special Needs Individuals, an entrance to the physical education, Dar 
Elsafaa for publishing and distribution

26- Aziz Magdy Ibrahim (2007): Learning Curriculums of those who are with Special Needs under their Basic, Social and Knowledge Requirements, Dar El Anglo, Cairo

27- Naglaa Fathy Khalifa (2007): Proposed Kinetic Program to Improve the Basic Kinetic Skills of the Optically Disabled Children before School, MBA, Faculty of Physical Education for Females, Alexandria University $\begin{array}{llr}\text { 28- Hanaa Abd } & \text { Elwahab } \\ \text { Hassan } & \text { (1986): } & \text { The }\end{array}$
Compatibility and Its Relation with the Performance Level in the Track and Racetrack Competitions, unpublished PHD desertion, Faculty of Physical Education for Males, Cairo, Helwan University. (30) 29- Hanaa Fayez Abd Elsalam (2008)" Optically Disabled Children who are Family Abused and Limit it by Using the Integrated Solution in Serving the Individual (Applied Study on Elnour Schools in Alexandria), PHD, Faculty of Arts, Alexandria University. 